\title{
Barriers associated with exercise and community access for individuals with stroke
}

\author{
James H. Rimmer, PhD; ${ }^{\text {* }}$ Edward Wang, PhD; ${ }^{2}$ Donald Smith, MS $^{2}$ \\ ${ }^{1}$ Department of Disability and Human Development and ${ }^{2}$ College of Nursing, University of Illinois at Chicago, Chicago, IL
}

\begin{abstract}
Increasing participation in physical activity among people with stroke continues to be a major challenge for healthcare professionals. We administered a survey to a group of 83 adults with unilateral stroke (mean age $=54.2 \mathrm{yr}$ ) to determine their perceived barriers to exercise. The five most common barriers in rank order were (1) cost of the program (61\%), (2) lack of awareness of a fitness center in the area (57\%), (3) no means of transportation to a fitness center (57\%), (4) no knowledge of how to exercise (46\%), and (5) no knowledge of where to exercise (44\%). The least common barriers were (1) lack of interest (16\%), (2) lack of time (11\%), and (3) concern that exercise would worsen their condition (1\%). People with stroke reported several barriers that prevented or reduced their participation in exercise. Healthcare professionals must identify and remove these barriers to promote greater participation in exercise among people with stroke.
\end{abstract}

Key words: environmental barriers, exercise, fitness center, health promotion, personal barriers, physical activity, physical disabilities, rehabilitation, stroke, survey.

\section{INTRODUCTION}

Physical activity participation among people with stroke and other disabling conditions is substantially lower than in the general population [1-2]. Several reports have noted that a sedentary lifestyle can precipitate functional decline in persons with stroke [3-5]. Reduced cardiorespiratory fitness associated with a lack of physical activity may be a secondary condition that limits the transfer of walking skills obtained during rehabilitation to the community [6]. Similarly, inadequate amounts of exercise can accelerate a person's functional decline and limit his or her ability to work, recreate, and engage in community events [7-8].

People with stroke are especially vulnerable to the effects of a sedentary lifestyle and would benefit greatly from increasing the amount of physical activity they regularly obtain [9-13]. Unfortunately, options for exercise and recreation are often limited by numerous personal (e.g., motivation, self-efficacy) [14-15] and environmental or facility barriers (e.g., inaccessible programs, equipment, and services offered in community recreation facilities) [16]. The Healthy People 2010: Understanding and Improving Health chapter "Disability and Secondary Conditions" noted that the significantly lower rate of participation among people with disabilities may be related to a variety of environmental and personal barriers, including architectural barriers, organizational policies

\footnotetext{
Abbreviation: B-PADS = Barriers to Physical Activity and Disability Survey.

*Address all correspondence to James $\mathrm{H}$. Rimmer, PhD; Director, Rehabilitation Engineering Research Center on Recreational Technologies and Exercise Physiology Benefiting Persons with Disabilities, National Center on Physical Activity and Disability, Department of Disability and Human Development, University of Illinois at Chicago, 1640 West Roosevelt Rd, Chicago, IL 60608; 312-413-9651; fax: 312-355-4058. Email: jrimmer@uic.edu DOI: 10.1682/JRRD.2007.02.0042
} 
and practices, discrimination, and social attitudes [16]. These barriers effectively reduce personal choice options, inhibit participation in healthy and active lifestyles, and prevent people with stroke and other disabilities from fully participating in their communities [17].

Rimmer et al. reported several different categories of environmental or facility barriers related to participation in physical activity among people with physical disabilities; these barriers included the built environment, cost of services or programs, equipment, policies, information, and education and training of fitness facility staff [18]. Personal factors are also associated with participation in physical activity. Shaughnessy et al. reported that among 312 stroke survivors, self-efficacy (i.e., individual's judgment that he or she can complete the activity), outcome expectations (i.e., a specific outcome will occur as a result of performing the behavior), and exercise history before the stroke directly or indirectly influenced exercise participation [14]. Developing recommendations for a large and diverse group of stroke survivors requires a broader and more comprehensive understanding of both personal and environmental/facility factors that may enhance or impede participation in physical activity [19].

A growing and important area of research involves the identification of "high level" factors that increase physical activity participation at both the person and environmental/facility levels [20-25]. Programs to promote physical activity in various populations have focused almost entirely on personal factors in isolation of the physical environment [26]. A systematic examination of personal and environmental/facility mediators of physical activity in persons with stroke requires a better understanding of the contextual factors (i.e., personal factors vs environmental/facility factors) associated with this population's participation in physical activity. Recommendations developed for the general population are likely to be ineffective for individuals with stroke since reduced mobility, secondary health conditions associated with stroke, and existing barriers to community access often limit these individuals' opportunities to engage in physical activity. Without an understanding of the critical person-environment barriers associated with participation in physical activity, establishing effective programs that have sustainable outcomes is difficult. This study examined the multidimensional nature of barriers to physical activity reported by people with stroke.

\section{METHODS}

\section{Participants}

The participants with stroke in this retrospective analysis were recruited to participate in a health promotion program at a major university-based medical center in the Midwest [27]. Before their participation in the study, participants were asked a series of questions related to their barriers to exercise. Participants were recruited from various clinics and hospitals in the surrounding community. To be included in the study, participants had to (1) be 30 to 70 years old, (2) be able to walk at least 50 feet without assistance, (3) be poststroke at least 6 months, and (4) have written permission to participate in the program from their physician. While most subjects had had a unilateral stroke and required an assistive aid (i.e., cane, walker, braces, and/or wheelchair), specific stroke deficits (i.e., motor, sensory, and speech) were not examined. Exclusion criteria were (1) score of 16 or less on the Mini-Mental State Examination and (2) primary disability unrelated to stroke. The institutional review board at the university-based medical center approved the study.

\section{Barriers to Physical Activity and Disability Survey}

We used the Barriers to Physical Activity and Disability Survey (B-PADS) (Appendix, available online only at http://www.rehab.research.va.gov) to collect data on the types of barriers (personal or environmental/facility) that individuals with disabilities experience related to exercise participation [17]. The B-PADS consists of 34 items, 31 of which have two response choices: yes or no. The remaining 3 items are open-ended, and 2 of these are follow-up questions that ask participants to explain a previous "yes" response. Trained project staff administered the surveys over the telephone. A training session on administration of the B-PADS preceded data collection. Each research assistant conducted five pilot telephone interviews with five different participants with stroke while the project coordinator listened on a third line to the administration of the survey and independently scored each item. The research assistants' scores were then compared with the project coordinator's scores. No significant scoring differences occurred. Test-retest stability for the 31 categorical items resulted in a Cohen $\kappa$ of 0.76 , and interrater reliability for two independent raters resulted in a Cohen $\kappa$ of 0.86 . The telephone survey took 30 to 45 minutes to complete. 


\section{Data Analysis}

Data were analyzed with graphical methods wherever applicable to facilitate data inspection and interpretation. Outliers and influential observations were identified and checked for accuracy. Data error due to data entry oversight was appropriately corrected. Data were summarized with appropriate descriptive statistics (e.g., mean and standard deviation for continuous variables, count and frequency for categorical variables). Subjects were divided into two groups on the basis of annual income: lower income $(<\$ 15,000)$ and higher income $(>\$ 15,000)$; selfreported barriers to physical activity were then tabulated and compared between the lower and higher income groups. The total number of barriers reported by each participant was summed and aggregated within each of the two income groups and the groups' mean and cumulative frequency values were compared. All statistical analyses were performed using SAS 9.1 statistical software (SAS Inc; Cary, North Carolina).

\section{RESULTS}

Table 1 shows the sample demographics of the participants with stroke $(n=83)$. The majority of subjects (mean age $=54.2 \mathrm{yr}$ ) were African American (80\%), female (70\%), and had an annual household income of $<\$ 15,000$ (65\%). Approximately two-thirds of the sample had a high school degree or less. A total of 77 percent were currently receiving disability benefits. In addition, 28 percent of the participants lived alone; 35 percent reported smoking; and 84 percent were obese or overweight, with an average body mass index of $34.5 \mathrm{~kg} / \mathrm{m}^{2}$.

The majority of participants were interested in starting an exercise program (96\%) and felt that an exercise program would help their condition (91\%). Nearly 80 percent of the participants said that they were told by their physician to exercise. This high percentage may be related to the physician encouraging the participant to perform certain poststroke rehabilitation exercises rather than offering general exercise recommendations to join a fitness center or participate in home-based conditioning exercises. While 90 percent of participants indicated that they had exercised at some point before their stroke, about 32 percent reported that they stopped exercising after their stroke because of health problems. Only one participant reported ever being injured from exercising.
Table 1.

Sample demographics of participants with stroke $(n=83)$.

\begin{tabular}{|c|c|}
\hline Characteristic & \% or Mean \pm SD \\
\hline \multicolumn{2}{|l|}{$\overline{\operatorname{Sex}}$} \\
\hline Male & 30 \\
\hline Female & 70 \\
\hline \multicolumn{2}{|l|}{ Race/Ethnicity } \\
\hline White & 9 \\
\hline African American & 80 \\
\hline Hispanic & 10 \\
\hline Other & 1 \\
\hline \multicolumn{2}{|l|}{ Income $(\$)^{*}$} \\
\hline$<15,000$ & 65 \\
\hline $15,000-24,999$ & 12 \\
\hline $25,000-49,999$ & 9 \\
\hline $50,000+$ & 3 \\
\hline \multicolumn{2}{|l|}{ Education } \\
\hline Less than High School & 26 \\
\hline High School & 35 \\
\hline Some College & 32 \\
\hline College or Higher & 7 \\
\hline \multicolumn{2}{|l|}{ Marital Status } \\
\hline Married & 28 \\
\hline Divorced or Separated & 41 \\
\hline Widowed & 8 \\
\hline Never Married & 23 \\
\hline \multicolumn{2}{|l|}{ Assistive Device Use $^{\dagger}$} \\
\hline Cane & 70 \\
\hline Braces & 23 \\
\hline Walker & 20 \\
\hline Wheelchair & 16 \\
\hline Living Alone (yes) & 28 \\
\hline Smoking (yes) & 35 \\
\hline Receiving Disability Benefits (yes) & 77 \\
\hline Age (yr) & $54.2 \pm 8.2$ \\
\hline Body Mass Index $\left(\mathrm{kg} / \mathrm{m}^{2}\right)$ & $34.5 \pm 10.1$ \\
\hline $\begin{array}{l}{ }^{*} 11 \% \text { refused to answer. } \\
{ }^{\dagger} \text { Some individuals reported using multiple de } \\
\text { SD = standard deviation. }\end{array}$ & \\
\hline
\end{tabular}

In Table 2, the barriers reported by participants are shown divided into two categories: environmental/facility barriers and personal barriers. Pertaining to environmental/facility barriers, 61 percent of the participants mentioned that the cost associated with joining a fitness facility was a barrier. The majority of participants (57\%) noted that they were unaware of an appropriate fitness facility in their neighborhood or community, and the same number of participants reported that they did not have a method of transportation to a fitness facility. More than 
Table 2.

Self-reported barriers to physical activity as reported by participants with stroke $(n=83)$ on Barriers to Physical Activity and Disability Survey.

\begin{tabular}{lc}
\multicolumn{1}{c}{ Barrier } & $\mathbf{\%}$ \\
\hline Environmental/Facility & 61 \\
Cost of the program & 57 \\
Lack of transportation & 57 \\
Not aware of fitness center in the area & 36 \\
Don’t feel trainer in facility is able to help & 26 \\
Not comfortable in exercising in a facility & \\
Personal & 46 \\
Don’t know how to exercise & 44 \\
Don’t know where to exercise & 39 \\
Lack of energy & 37 \\
Lack of motivation & 36 \\
Exercise won’t improve my condition & 33 \\
I’m too lazy to exercise & 28 \\
Health concerns prevent me from exercising & 20 \\
Exercise is too difficult & 18 \\
Exercise is boring or monotonous & 16 \\
Lack of interest & 11 \\
Lack of time & 1 \\
Exercise will make my condition worse
\end{tabular}

one-third (36\%) of the participants felt that a personal trainer or exercise instructor in a fitness facility would be unable to help them, and about one-fourth (26\%) felt uncomfortable exercising in a fitness facility.

The most common personal barriers reported were (1) “don't know how to exercise" (46\%) and (2) “don't know where to exercise" (44\%). These barriers were followed in rank order by "lack of energy" (39\%), "lack of motivation" (37\%), "exercise won't improve my condition" (36\%), and "I'm too lazy to exercise” (33\%). One of the most common barriers to exercise participation reported among nondisabled populations is lack of time [28]. However, lack of time was one of the lowest barriers reported by our participants with stroke (11\%).

Further analysis of the data revealed that the primary barriers to exercise in persons with stroke varied by income group. Figure 1 illustrates the top six barriers reported by participants in the lower $(<\$ 15,000)$ and relatively higher $(>\$ 15,000)$ income groups. Nearly 80 percent of the lower income group identified cost as the primary barrier to exercise, and about 70 percent cited lack of transportation as another major barrier. In contrast, approximately 50 and 40 percent of stroke participants in the higher income group reported cost and lack of transportation, respectively, as major barriers to exer- cise. Interestingly, more than 40 percent of participants in the higher income group reported that an exercise program would not improve their condition, while the lower income group did not cite this as a common barrier. Approximately the same proportion of participants in each group reported not knowing where and how to exercise as other key barriers.

On average, participants with stroke reported 4.3 barriers that prevented them from engaging in physical activity. People in the lower income group reported slightly more barriers than the higher income group (4.6 vs 3.9, respectively). As shown in Figure 2, approximately 40 percent of participants in the lower income group reported four or fewer barriers, while approximately 70 percent of participants in the higher income group reported four or fewer barriers. Overall, about 50 percent of the participants with stroke reported five or more barriers to exercise.

\section{DISCUSSION}

Our findings revealed that a group of predominantly African-American female adults with stroke who resided in a large urban city (Chicago) reported multiple barriers to participation in physical activity. The two major barriers reported were the cost associated with joining a fitness facility and transportation to a fitness facility. Lack of time, one of the highest-ranked barriers to participation in physical activity among nondisabled adults [29-31], was not listed as a primary barrier in our cohort. This finding may have reflected the high percentage of participants who were not employed. Our findings were, in general, consistent with previous research that involved a predominantly African-American group of women with physical disabilities, including arthritis (30\%), stroke (22\%), and multiple sclerosis (14\%) [17]. In that study, the four highest barriers were cost of the exercise program (84.0\%), lack of energy (65.8\%), transportation (60.5\%), and not knowing where to exercise (57.9\%) [17].

The multitude of personal and environmental/facility barriers that our participants with stroke reported leads us to several suggestions for helping individuals with stroke and/or their caregiver overcome these barriers. First, healthcare professionals must systematically identify personal and environmental/facility barriers to exercise when referring patients with stroke from rehabilitation to community-based exercise. The B-PADS is a relatively 
(a)

\section{$\frac{\text { 은 }}{\frac{1}{\pi}}$}

(a)

(b)

Don't know where to exercise
๓⿴囗十
Exercise won't improve my condition

Don't know how to exercise

\section{Lack of transportation}

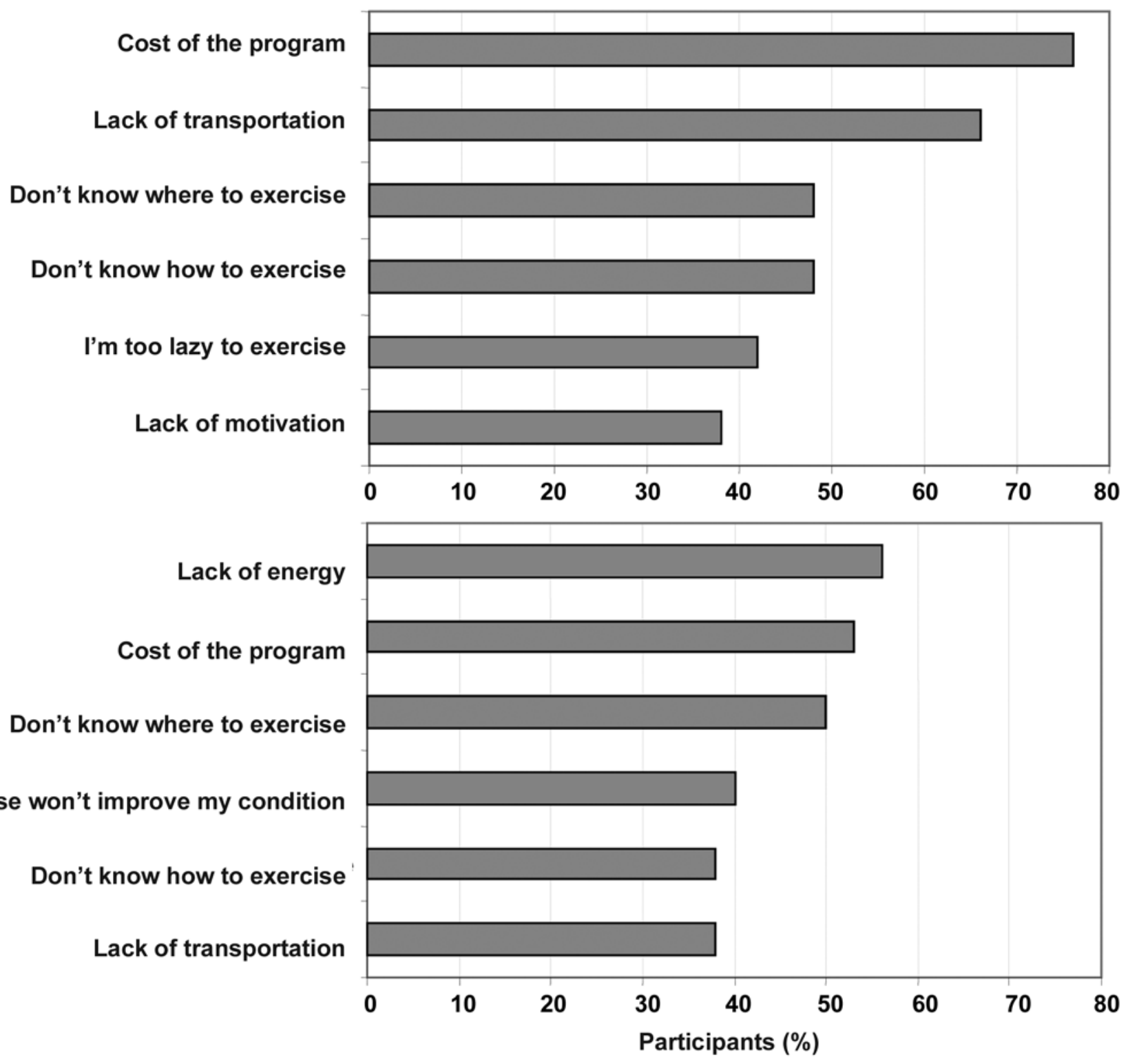

Figure 1.

Top six barriers to physical activity reported by participants with stroke in (a) lower income $(<\$ 15,000)$ and $(\mathbf{b})$ higher income $(>\$ 15,000)$ groups.

short instrument that can help professionals identify these key barriers to exercise participation. Identifying these barriers will help the professionals formulate a home- or community-based exercise plan founded on the participant's response pattern. For example, if the participant lists cost of joining a fitness facility and transportation to a fitness facility as major barriers, the professional might want to recommend a home-based exercise program that does not require the purchase of expensive equipment or a fitness club membership. This home-based program may involve the participant going for a few short walks during the day, getting up and walking around the house or apartment during commercials, using an exercise video designed for older adults or persons with stroke (e.g., chair exercises), and using various household items (e.g., water-filled milk containers) to increase muscle strength. The National Center on Physical Activity and Disability recently developed a new exercise video for people with stroke (http://www.ncpad.org). We also recommend that when a participant discontinues a program, 
JRRD, Volume 45, Number 2, 2008

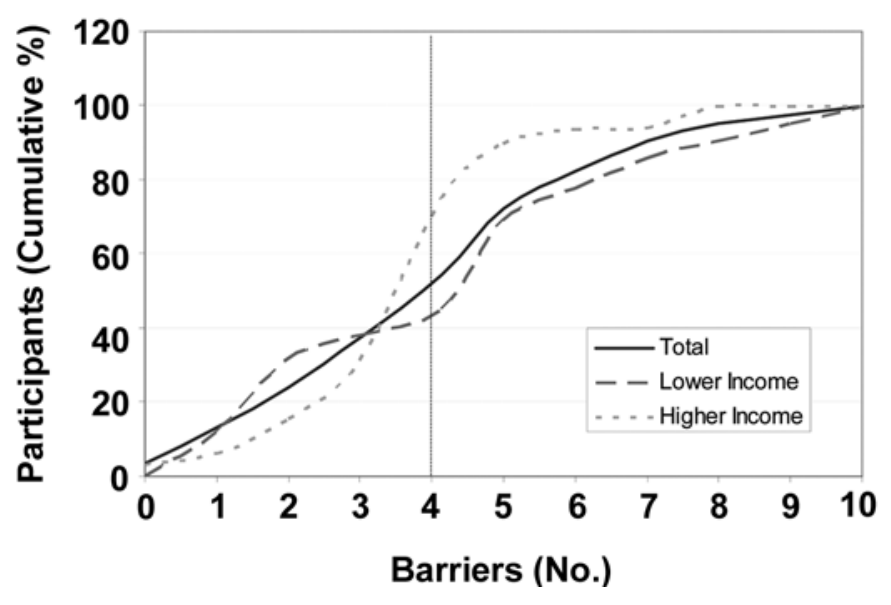

Figure 2.

Number of barriers to physical activity reported by participants with stroke. Lower income $=<\$ 15,000 / \mathrm{yr}$, higher income $=>\$ 15,000 / \mathrm{yr}$.

the professional implement a new B-PADS to determine whether any new or additional factors are associated with the participant's discontinuation.

Second, the same barrier (e.g., transportation) reported by several participants may have a different set of contextual factors for each individual. For example, one person may cite transportation as a barrier because he or she has difficulty getting up and down the steps on a bus, another individual may report that paying for transportation to an exercise facility is too costly, and a third person may state that the bus stop is too far from his or her home. When assessing barriers to participation in exercise, we recommend a subset of follow-up items that probe the specific reason for the reported barrier.

Third, while our participants expressed great interest in participating in an exercise program, the preponderance of research on the fitness levels of people with stroke indicates that they are unlikely to be participating in a structured physical activity program and, as a group, are considered severely deconditioned [10,13-14,32-33]. Therefore, the amount of exercise that a person with stroke thinks is implied by "structured exercise program" may be less than the dose recommended to confer health benefits or less than the public health guidelines of 30 minutes a day of moderate physical activity most days of the week.

Finally, customizing physical activity programs for persons with stroke is clearly needed to remove as many personal and environmental/facility barriers as possible. Barrier identification and removal should be based on the various impairments and/or activity limitations associated with stroke severity. Environmental assessment tools that measure barriers in the built environment (e.g., home, neighborhood, community fitness center) are available to help professionals identify barriers before initiating an exercise program for this population [34]. The combined identification and removal of personal and environmental/facility barriers may effectively tailor the program to the individual and his or her environment and enhance the likelihood that he or she will successfully participate in a structured exercise program.

The study had several limitations. First, our findings are not representative of a broader population of stroke survivors. Most of the participants were African American and female, resided in a large urban city (Chicago), and were predominantly low income. We would be interested to discover in future research whether participants in other settings (i.e., rural, suburban) and subgroups (i.e., different cultural and sociodemographic strata) would report a similar number and type of barriers. Costassociated barriers would likely not be as great an issue with higher socioeconomic groups, but this fact has never been examined in a stroke cohort. Second, the participants with stroke who completed the survey were interested in participating in a health promotion research study and were preparing for enrollment in the study. Not clear is whether people with stroke who were not interested in participating in the study would have reported similar or different barriers. Third, the barriers instrument that we used (B-PADS) did not include questions about the participants' self-efficacy for exercise and exercise history. Both Shaughnessy et al. [14] in a stroke population and Kinne et al. [15] in a cohort with mobility impairments reported that exercise self-efficacy was associated with exercise participation. Shaughnessy et al. also found that exercise history before the stroke was associated with participation in exercise after the stroke [14]. Low exercise self-efficacy and poor exercise history before a stroke could be substantial barriers to participation in exercise after a stroke.

\section{CONCLUSIONS}

People with stroke continue to engage in higher rates of sedentary behavior and have significantly lower levels of physical fitness and a thinner margin of health than the general population [32]. Despite the well-established physical and psychosocial benefits associated with regular participation in moderate levels of physical activity, 
people with stroke present a significant number of barriers to participation in the types of physical activity they need to maintain health and wellness.

Because our stroke cohort identified the cost of fitness programs, transportation, and lack of awareness and understanding of where or how to exercise as major barriers, Federal agencies, policy makers, and local communities should consider subsidizing fitness memberships and transportation for people with stroke and other disabilities so that these individuals have the opportunity to selfmanage their health. For many individuals living in urban settings, crime, safety, weather, damaged sidewalks, and poor health make exercising outdoors extremely difficult and lack of exercise equipment in the home leaves little opportunity for them to participate in regular exercise. A need also exists for managers and directors of local fitness facilities and health clubs to actively recruit new members among the disability community. Social marketing efforts should include people with and without disabilities exercising together in the same facility to help offset the lack of role models in much of the advertising media used by health clubs and fitness centers [35]. Adequate levels of physical activity are unlikely to be obtained by a large percentage of the population with stroke without an effective public health campaign that addresses cost and transportation barriers as well as increased public awareness of the importance of exercise for persons with stroke.

An important area of future research is for investigators to better quantify the magnitude of change in health and function among persons with stroke after certain barriers are removed. Whether removal of key barriers would facilitate sustainable participation in physical activity among this cohort is unknown, as is whether new or additional personal or environmental/facility barriers would result from removing certain barriers (e.g., transportation and cost barriers are eliminated to allow a participant to join a health club but he or she does not feel comfortable in the exercise setting or does not enjoy the program). Research on barrier removal and adherence to physical activity among persons with stroke should be examined within a longitudinal framework, since many barriers are likely to change across time (e.g., change in health status) and settings (e.g., moving to a new residence).

\section{ACKNOWLEDGMENTS}

This material was based on work supported by the National Institutes of Health, National Center on Medical
Rehabilitation Research (grant HHS5R21HD40988), and the National Institute on Disability and Rehabilitation Research, Rehabilitation Engineering Research Center on Recreational Technologies and Exercise Physiology for People with Disabilities (grant H133E070029).

The authors have declared that no competing interests exist.

\section{REFERENCES}

1. Rimmer JH, Rubin SS, Braddock D, Hedman G. Physical activity patterns of African-American women with physical disabilities. Med Sci Sports Exerc. 1999;31(4):613-18. [PMID: 10211861]

2. U.S. Department of Health and Human Services. The 2005 Surgeon General's call to action to improve the health and wellness of persons with disabilities: What it means to you. Washington (DC): Office of the Surgeon General; 2005.

3. Rimmer JH. Exercise and physical activity in persons aging with a physical disability. Phys Med Rehabil Clin N Am. 2005;16(1):41-56. [PMID: 15561544]

4. Macko RF, Ivey FM, Forrester LW, Hanley D, Sorkin JD, Katzel LI, Silver KH, Goldberg AP. Treadmill exercise rehabilitation improves ambulatory function and cardiovascular fitness in patients with chronic stroke: A randomized, controlled trial. Stroke. 2005;36(10):2206-11. [PMID: 16151035]

5. Eng JJ, Chu KS, Kim CM, Dawson AS, Carswell A, Hepburn KE. A community-based group exercise program for persons with chronic stroke. Med Sci Sports Exerc. 2003; 35(8):1271-78. [PMID: 12900678]

6. Kelly JO, Kilbreath SL, Davis GM, Zeman B, Raymond J. Cardiorespiratory fitness and walking ability in subacute stroke patients. Arch Phys Med Rehabil. 2003;84(12): 1780-85. [PMID: 14669183]

7. Kerstin W, Gabriele B, Richard L. What promotes physical activity after spinal cord injury? An interview study from a patient perspective. Disabil Rehabil. 2006;28(8):481-88. [PMID: 16513581]

8. Cress ME, Buchner DM, Prohaska T, Rimmer J, Brown M, Macera G, Dipietro L, Chodzko-Zajko W. Best practices for physical activity programs and behavior counseling in older adult populations. J Aging Phys Act. 2005;13(1):61-74. [PMID: 15677836]

9. Duncan P, Richards L, Wallace D, Stoker-Yates J, Pohl P, Luchies C, Ogle A, Studentski S. A randomized, controlled pilot study of a home-based exercise program for individuals with mild and moderate stroke. Stroke. 1998;29(10): 2055-60. [PMID: 9756581]

10. Ivey FM, Hafer-Macko CE, Macko RF. Exercise rehabilitation after stroke. NeuroRx. 2006;3(4):439-50.

[PMID: 17012057] 
11. Chu KS, Eng JJ, Dawson AS, Harris JE, Ozkaplan A, Gylfadóttir S. Water-based exercise for cardiovascular fitness in people with chronic stroke: A randomized controlled trial. Arch Phys Med Rehabil. 2004;85(6):870-74. [PMID: 15179638]

12. Rimmer JH, Riley B, Creviston T, Nicola T. Exercise training in a predominantly African-American group of stroke survivors. Med Sci Sports Exerc. 2000;32(12):1990-96. [PMID: 11128841]

13. Rimmer JH, Wang E. Aerobic exercise training in stroke survivors. Top Stroke Rehabil. 2005;12(1):17-30. [PMID: 15735998]

14. Shaughnessy M, Resnick BM, Macko RF. Testing a model of post-stroke exercise behavior. Rehabil Nurs. 2006;31(1): 15-21. [PMID: 16422040]

15. Kinne S, Patrick DL, Maher EJ. Correlates of exercise maintenance among people with mobility impairments. Disabil Rehabil. 1999;21(1):15-22. [PMID: 10070599]

16. U.S. Department of Health and Human Services. Healthy people 2010: Understanding and improving health. 2nd ed. Washington (DC): U.S. Department of Health and Human Services; 2000.

17. Rimmer JH, Rubin SS, Braddock D. Barriers to exercise in African American women with physical disabilities. Arch Phys Med Rehabil. 2000;81(2):182-88. [PMID: 10668772]

18. Rimmer JH, Riley B, Wang E, Rauworth A, Jurkowski J. Physical activity participation among persons with disabilities: Barriers and facilitators. Am J Prev Med. 2004;26(5):419-25. [PMID: 15165658]

19. Rimmer JH. Use of the ICF in identifying factors that impact participation in physical activity/rehabilitation among people with disabilities. Disabil Rehabil. 2006; 28(17):1087-95. [PMID: 16950739]

20. Dunn AL, Andersen RE, Jakicic JM. Lifestyle physical activity interventions. History, short- and long-term effects, and recommendations. Am J Prev Med. 1998;15(4):398-412. [PMID: 9838980]

21. Giles-Corti B, Donovan RJ. The relative influence of individual, social and physical environment determinants of physical activity. Soc Sci Med. 2002;54(12):1793-1812. [PMID: 12113436]

22. Bauman AE, Sallis JF, Dzewaltowski D, Owen N. Toward a better understanding of the influences on physical activity: The role of determinants, correlates, causal variables, mediators, moderators, and confounders. Am J Prev Med. 2002;23(2 Suppl):5-14. [PMID: 12133733]

23. Carnegie MA, Bauman A, Marshall AL, Mohsin M, Westley-Wise V, Booth ML. Perceptions of the physical environment, stage of change for physical activity, and walking among Australian adults. Res Q Exerc Sport. 2002;73(2): 146-55. [PMID: 12092889]

24. Sallis J, Kraft K, Linton LS. How the environment shapes physical activity: A transdisciplinary research agenda. Am J Prev Med. 2002;22(3):208. [PMID: 11897466]
25. Lewis BA, Marcus BH, Pate RR, Dunn AL. Psychosocial mediators of physical activity behavior among adults and children. Am J Prev Med. 2002;23(2 Suppl):26-35.

[PMID: 12133735]

26. Satariano WA, McAuley E. Promoting physical activity among older adults: From ecology to the individual. Am J Prev Med. 2003;25(3 Suppl 2):184-92. [PMID: 14552943]

27. Rimmer JH, Braunschweig C, Silverman K, Riley B, Creviston T, Nicola T. Effects of a short-term health promotion intervention for a predominantly African-American group of stroke survivors. Am J Prev Med. 2000;18(4): 332-38. [PMID: 10788737]

28. Dishman RK. Motivating older adults to exercise. South Med J. 1994;87(5):S79-82. [PMID: 8178208]

29. Johnson CA, Corrigan SA, Dubbert PM, Gramling SE. Perceived barriers to exercise and weight control practices in community women. Women Health. 1990;16(3-4):177-91. [PMID: 2267806]

30. Nelson JP. Perceived health, self-esteem, health habits, and perceived benefits and barriers to exercise in women who have and have not experienced stage I breast cancer. Oncol Nurs Forum. 1991;18(7):1191-97. [PMID: 1945965]

31. Dishman RK. Advances in exercise adherence. Champaign (IL): Human Kinetics; 1994.

32. Gordon NF, Gulanick M, Costa F, Fletcher G, Franklin BA, Roth EJ, Shephard T; American Hearth Association Council on Clinical Cardiology, Subcommittee on Exercise, Cardiac Rehabilitation, and Prevention; the Council on Cardiovascular Nursing; the Council on Nutrition, Physical Activity, and Metabolism; and the Stroke Council. Physical activity and exercise recommendations for stroke survivors: An American Heart Association scientific statement from the Council on Clinical Cardiology, Subcommittee on Exercise, Cardiac Rehabilitation, and Prevention; the Council on Cardiovascular Nursing; the Council on Nutrition, Physical Activity, and Metabolism; and the Stroke Council. Circulation. 2004;109(16):2031-41. [PMID: 15117863]

33. Ivey FM, Macko RF, Ryan AS, Hafer-Macko CE. Cardiovascular health and fitness after stroke. Top Stroke Rehabil. 2005;12(1):1-16. [PMID: 15735997]

34. Rimmer J, Riley B, Wang E, Rauworth A. Development and validation of AIMFREE: Accessibility Instruments Measuring Fitness and Recreation Environments. Disabil Rehabil. 2004;26(18):1087-95. [PMID: 15371034$]$

35. Rimmer JH. The conspicuous absence of people with disabilities in public fitness and recreation facilities: Lack of interest or lack of access? Am J Health Promot. 2005; 19(5):327-29. [PMID: 15895533]

Submitted for publication February 26, 2007. Accepted in revised form June 18, 2007. 